\section{CLINICAL AUDIT ON THE DIAGNOSTIC YIELD OF BRUSHING CYTOLOGY IN BILIARY AND PANCREATIC MALIGNANCY DETECTED ON ERCP AND EUS}

S Anwar, H Mushtaq, N Ullah, S McKiernan Department of Clinical Medicine \& Gastroenterology Trinity College Dublin, Ireland; St James's Hospital, Dublin, Ireland

\subsection{6/gutjnl-2013-305143.53}

Introduction Patients with suspected pancreatobiliary malignancy on radiological imaging are often referred for endoscopic investigations with a view to obtain a definitive histological diagnosis.

Aims/Background To evaluate the diagnostic yield of brush cytology in biliary and pancreatic malignancy detected on ERCP and EUS.

Method We collected data from 01/01/2012 to 31/12/2012. 56 patients in total had brushings done at ERCP. Most common indications for ERCP were malignancy(68\%) CBD stones $(23 \%)$ pancreatitis(7\%) and cholangitis (2\%).Out of these 56 patients 38 had EUS and 30 patients had FNA.

Results 56 patients had ERCP brushings done, 30 were suspected of malignancy by radiology. Definite diagnosis of malignancy was in 23 patients, 6 had inflammatory stricture and one patient had PSC, of the remaining 26 patients 15 had CBD stones, five had chronic pancreatitis, three had cholangitis and three had stent insertion due to indeterminate stricture. The sensitivity of biliary brushings were $74 \%$ and specificity of $93 \%$, $26 \%$ had false negative results and all these patients had positive FNA. 38 patients had EUS done eight had inflammatory changes and 30 patients had FNA done. FNA was positive in 18 patients so the sensitivity was $78 \%$ and specificity was $100 \%$. Five patients had false negative FNA (Positive ampullary biopsies) four had chronic pancreatitis, two had cholangitis and one had PSC.

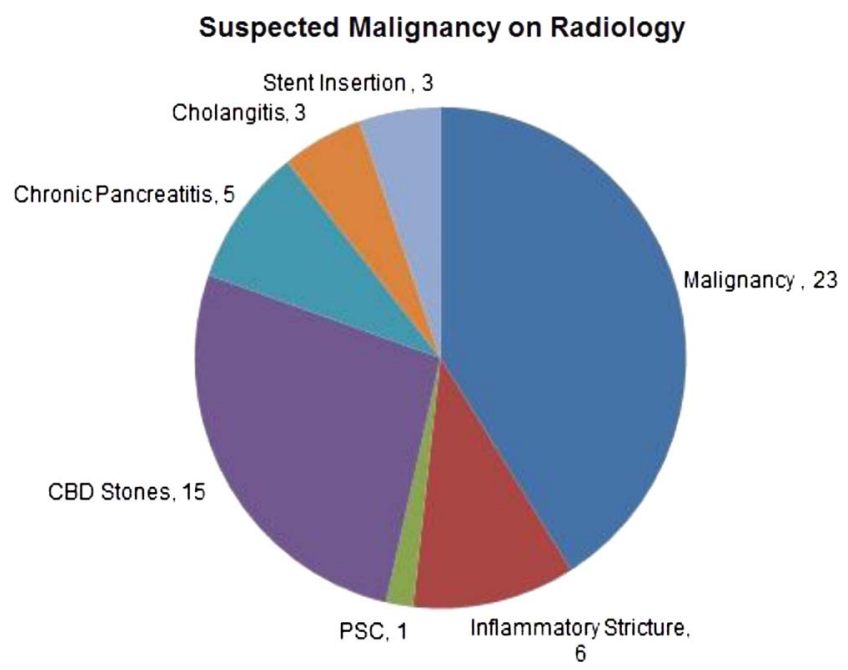

Figure 1 


\section{Abstracts}

Conclusion Brush cytology, in conjunction with EUS-FNA and radiological investigations, is a useful technique in the assessment of patients with suspected pancreatobiliary neoplasia.(1234)

\section{REFERENCES}

1 Rabinovitz $M$, Zajko $A B$, Hassanein $T$, et al. Diagnostic value of brush nosis of bile duct carcinoma: a study in 65 patients with bile duct strictures. Hepatology 1990;12:747-752.

2 Stewart CJ, Mills PR, Carter R, et al. Brush cytology in the assessment of pancreatico-biliary strictures: a review of 406 cases. J Clin Pathol. 2001;54:449-455

3 Eloubeidi MA, Chen VK, Jhala NC, et al. Endoscopic ultrasound-guided fine needle aspiration biopsy of suspected cholangiocarcinoma. Clin Gastroenterol Hepatol 2004;2:209-213.

4 Chang KJ, Nguyen P, Erickson RA, et al. The clinical utility of endoscopic ultrasound-guided fine-needle aspiration in the diagnosis and staging of pancreatic carcinoma. Gastrointest Endosc. 1997;45:387-393. 